\title{
Non-coding RNA: a potential biomarker and therapeutic target for sepsis
}

\author{
Tie-Ning Zhang ${ }^{1}$, Da $\mathrm{Li}^{2}$, Jing Xia ${ }^{1}$, Qi-Jun Wu${ }^{3}$, Ri Wen ${ }^{1}$, Ni Yang ${ }^{1}$ and Chun-Feng \\ Liu $^{1}$ \\ ${ }^{1}$ Department of Pediatrics, PICU, Shengjing Hospital of China Medical University, Shenyang, China \\ ${ }^{2}$ Department of Obstetrics and Gynecology, Shengjing Hospital of China Medical University, Shenyang, China \\ ${ }^{3}$ Department of Clinical Epidemiology, Shengjing Hospital of China Medical University, Shenyang, China \\ Correspondence to: Chun-Feng Liu, email: zhliu258@hotmail.com \\ Keywords: sepsis, non-coding RNA, biogenesis, biomarkers, therapeutic target \\ Received: April 28, $2017 \quad$ Accepted: September 03, $2017 \quad$ Published: October 10, 2017 \\ Copyright: Zhang et al. This is an open-access article distributed under the terms of the Creative Commons Attribution License 3.0 \\ (CC BY 3.0), which permits unrestricted use, distribution, and reproduction in any medium, provided the original author and source \\ are credited.
}

\section{ABSTRACT}

Sepsis, a syndrome of physiologic, pathologic, and biochemical abnormalities caused by an altered systemic host response to infection, has become the main cause of death among patients admitted to the intensive care units. Recently, genome-wide expression analysis revealed that over $80 \%$ of the essential genetic elements were altered in critically ill patients. Notably, non-coding RNAs, including microRNAs, long non-coding RNAs and circular RNAs, have been proven to play essential roles in innate immunity, mitochondrial dysfunction and organ dysfunction. In this review, we introduced the biogenesis of non-coding RNAs briefly and summed up different kinds of non-coding RNAs in regulation of sepsis, which could provide a more comprehensive understanding about pathogenesis of the disease. Additionally, we summarized the limitations of current biomarkers and then recommended some non-coding RNAs as novel potential biomarkers for sepsis and sepsis-induced organ dysfunction. Besides, we also introduced some problems and challenges that need to be overcome during the clinical application of non-coding RNAs. Future research should focus on elucidating their molecular mechanisms, particularly long non-coding RNAs as well as circular RNAs and sepsis, to further understanding of the disease process. With the in-depth understanding of the mechanism of sepsis, non-coding RNAs provide a new insight into sepsis and could become the novel therapeutic targets in the future.

\section{INTRODUCTION}

Sepsis is a syndrome of physiological, pathological and biochemical abnormalities because of an altered systemic host response to infection [1, 2]. Nowadays, sepsis and septic shock have become major public health problems, being the main cause of death among patients admitted to the intensive care units [3, 4]. Each year, millions of people are affected by sepsis and the reported incidence of sepsis is increasing worldwide $[3,5,6]$ despite improvements in intensive care treatments. The study conducted by Zhou et al showed that the standardized occurrence rate was 461,68 , and 52 cases per 100,000 populations for sepsis, severe sepsis, and septic shock, respectively [7]. Besides, the study preformed by Martin et al found that there were 10,319,418 reported cases of sepsis (accounting for 1.3 percent of all hospitalizations) during a 22-year study period in the United State [8]. The outcome and prognosis for septic patients are unsatisfactory and clinical studies have showed that in-hospital mortality from septic shock might reach approximately $40 \%$ $[1,3]$. In addition, patients who survive sepsis often suffer from long-term physical, psychological and cognitive disabilities [9]. Study showed that incident severe sepsis 
was associated with a clinically and statistically significant increase in moderate to severe cognitive impairment among survivors [9]. Consequently, critical care specialists are aware of this disease, attempting to diagnose it at an early stage and manage septic patients more rationally.

According to the latest guidelines, fluid resuscitation, antimicrobial therapy, vasoactive mediation, and if necessary, a supportive therapy for organ dysfunction are recommended for the treatment of sepsis and septic shock [3]. Moreover, considering sepsis as medical emergencies, the latest guidelines recommend early diagnosis and that treatment should begin immediately [3]. However, the sensitivity and specificity of current biomarkers for the early diagnosis of sepsis, such as C-reaction protein (CRP), procalcitonin (PCT) and interleukin-6 (IL-6) are limited [10, 11], as they have been implicated in other non-inflammatory processes [12]. Recently, genome-wide expression analysis revealed that over $80 \%$ of the essential genetic elements were altered in critically ill patients [13]. Notably, a class of non-coding RNAs, including microRNAs (miRNAs), long non-coding RNAs (lncRNAs) and circular RNAs (circRNAs) have been identified as regulators of different signalling pathways and therefore, referred to as regulator
RNAs [14]. Based on in vivo and in vitro experiments, these molecules have been proven to play essential roles in innate immunity, mitochondrial dysfunction and organ dysfunction [15-20]. Consequently, it has been suggested that these noncoding RNAs are potential biomarkers or therapeutic targets for sepsis [21, 22].

Here in, this review will discuss how non-coding RNAs affect the pathogenesis of sepsis and their potential use as biomarkers or therapeutic targets for sepsis.

\section{BIOGENESIS OF NON-CODING RNA}

\section{Biogenesis of miRNAs}

MiRNAs are endogenous non-coding RNA molecules of approximate 19-22 nucleotides in length [23]. The biogenesis of miRNAs has been described in previous reviews $[14,24]$. Briefly, they are mainly transcribed by RNA polymerase II resulting in a primary miRNA (called pri-miRNA) with 500-3000 nucleotides [25] (Figure 1). The pri-miRNA is then cleaved into a premature miRNA (called pre-miRNA) 70-80 nucleotides in length by the "microprocessor complex", which consists

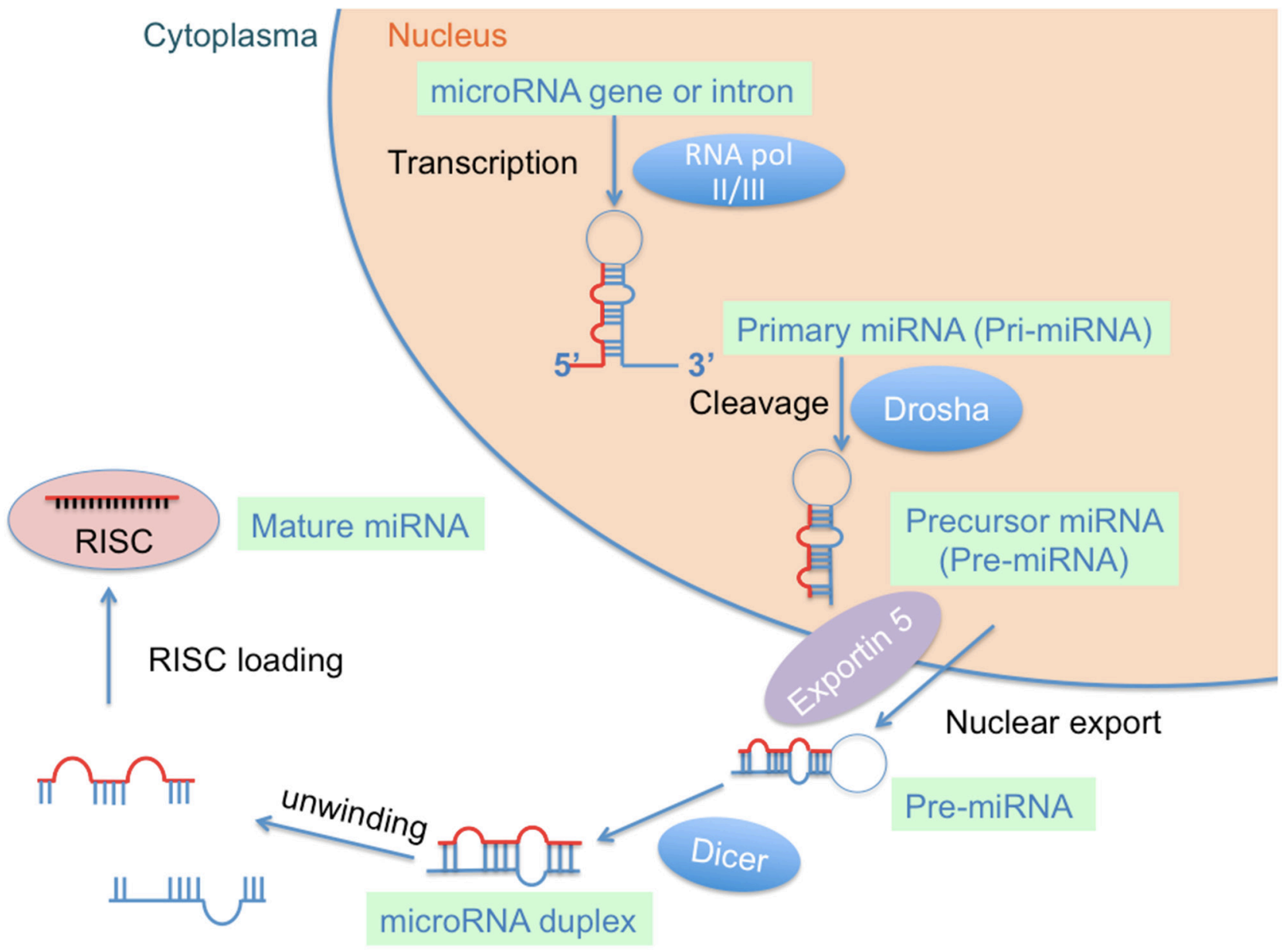

Figure 1: Biogenesis of microRNA (miRNA). 
of the RNase III Dorsha enzyme and the DiGeorge Syndrome Critical Region 8 (DGCR) protein [26]. The pre-miRNA is exported into the cytoplasm with the help of the nuclear export transporter, exportin 5, processing about 22 nucleotides "miRNA duplex" by interacting with RNase III endonuclease Dicer protein and the cofactor double-stranded transactivation-responsive RNAbinding protein [27]. The miRNA duplex is integrated into the "RNA-induced silencing complex" (RISC) after binding to the argonaute protein and a glycine tryptophan repeat-containing protein, where they bind to partial or full-complementary sequences in the 3' or 5' UTR of the target mRNA [28, 29]. MiRNAs have been demonstrated to participate in the comprehensive network of gene regulation in the pathophysiological processes of many diseases $[30,31]$.

\section{Biogenesis of IncRNA}

LncRNAs are a class of non-protein-coding transcripts larger than $200 \mathrm{nt}$ in length [32]. According to the latest version of LNCipedia, a database for annotated human lncRNA transcript sequences and structures, there are over 60,000 members of the lncRNA family that have been catalogued [33, 34]. Notably, the primary sequence of IncRNAs is poorly conserved, but it can be partially compensated through a high degree of structural conservation [35]. Furthermore, lncRNAs can be transcribed from conserved genomic regions [36] and back-splicing of exons, which could form circRNAs, can also generate lncRNAs [37, 38]. LncRNAs take part in some important functions of cells including chromatin rearrangement, histone modification, and modification of alternative splicing genes, as well as the regulation of gene expression. Therefore, IncRNAs play important role in the pathogenesis of various diseases $[39,40]$.

\section{Biogenesis of circRNA}

Initially, circRNAs were generally considered to be of low abundance but recent high-throughput sequencing and novel computational approaches have since shown them to be widespread and substantial within transcriptomes [37, 38, 41]. CircRNAs mainly come from the exons of protein-coding genes and they are not formed by the normal model of RNA splicing [42]. They are characterized by covalently closed loop structures through joining the 3' and 5' end together by exon circularization

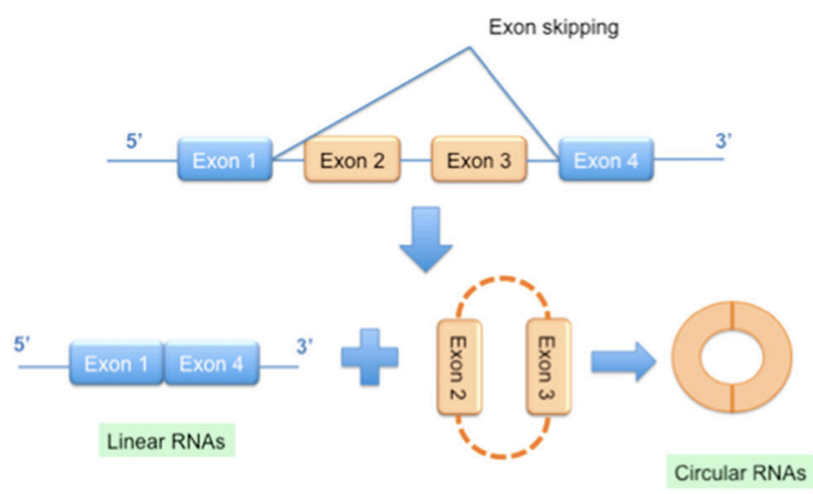

a. lariat-driven circularization

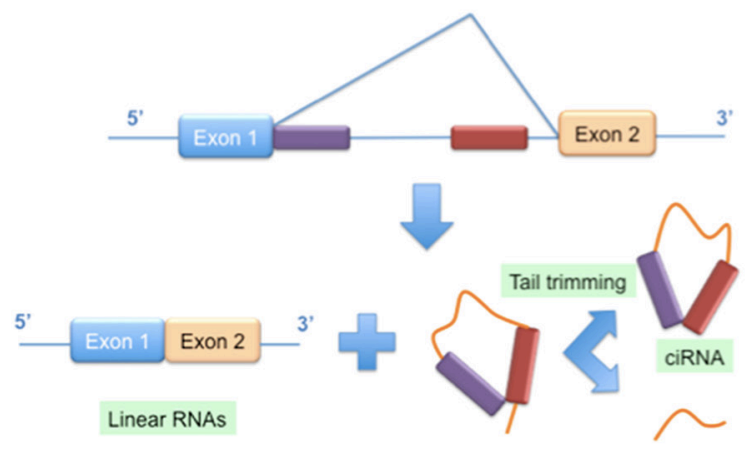

c. Circular intronic RNAs

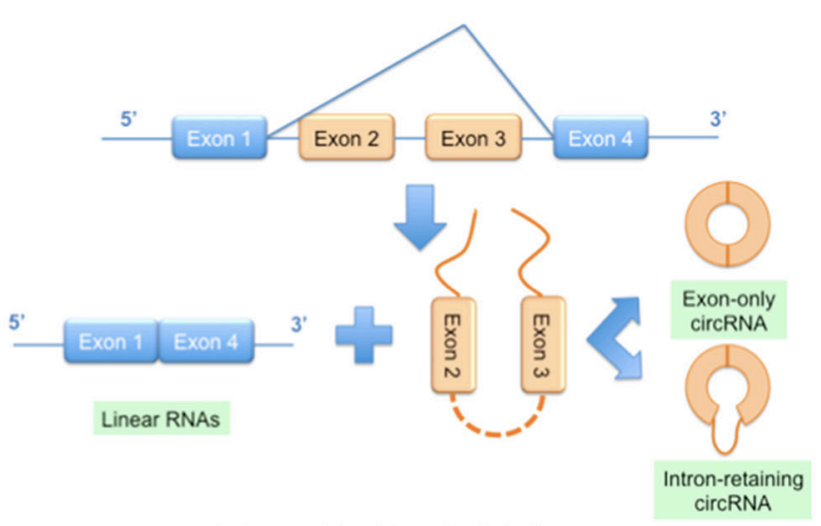

b. Intron-pairing-driven circularization

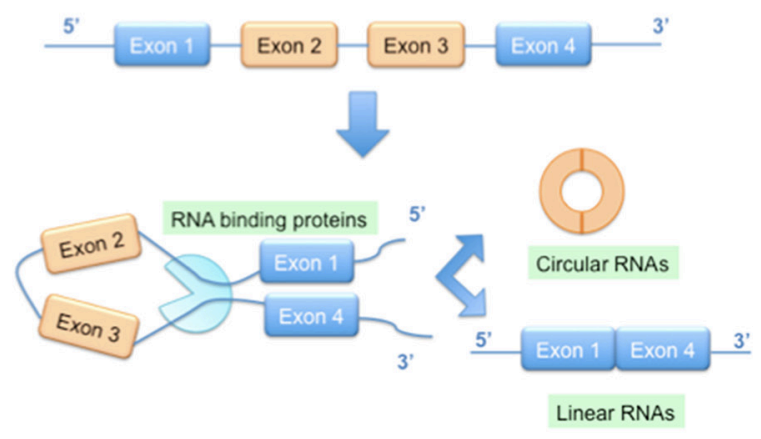

d. RNA binding proteins (RBPs) driven circularization

Figure 2: Models of circular RNA (circRNA) biogenesis. (A) Lariat-driven circularization; (B) Intron-pairing-driven circularization; (C) Circular intronic RNAs; (D) RNA binding proteins (RBPs) driven circularization. 
or intron circularization $[41,43]$. A study conducted by Jeck et al. showed that circRNAs were formed via two different mechanisms of exon circularization, lariat-driven circularization and intron-pairing-driven circularization [37] (Figure 2A \& 2B). As for introns between exons, when they form a circular structure, they will be removed or retained to form an exon-only circRNA or intronretaining circRNA called EIciRNA [37, 44] (Figure 2C). Furthermore, circRNAs can also be generated from the circularization of two flanking intronic sequences [45, 46] (Figure 2D). Recently, many circRNAs have been successfully identified in various tissues or organs and some have been linked to disease, suggesting that circRNAs are not simply by-products of mis-splicing or splicing errors $[16,43]$.

\section{NON-CODING RNAS IN THE DEVELOPMENT OF SEPSIS}

Non-coding RNAs are linked and also appear variational trend during the pathogenesis of sepsis. Up to now, most studies concentrate on the relationship between miRNAs and sepsis, only a few studies have investigated the relationship between lncRNA/circRNA and sepsis [14].

\section{Regulation of miRNAs in sepsis}

It is well-accepted that miRNAs play important roles in the innate and adaptive immunity during the pathogenesis of different diseases [47]. MiRNAs can modulate T helper cell and regulatory $\mathrm{T}$ cell development, which are critical in the process of controlling the host response to disease [48, 49]. During the process of sepsis, the host immune system will appear in pro-inflammatory and immunosuppressed states $[50,51]$. Several cytokines are produced in proinflammatory state during sepsis, such as the representative and most familiar, tumor necrosis factor- $\alpha$ (TNF- $\alpha$ ). The production of TNF- $\alpha$ is controlled by miRNAs at transcriptional and translational levels. For example, a study conducted by Dan et al. showed that upregulation of miR-181 could enhance TNF- $\alpha$ mRNA degradation [52]. Similarly, Huang et al. reported that miR-125b decreased significantly in association with higher TNF- $\alpha$ expression by neonatal monocytes after lipopolysaccharide (LPS) stimulation [53]. Moreover, miRNAs can directly target the TNF pathway and mediate the inflammatory reaction. For instance, Puimege et al. demonstrated that miR-511 is a genuine TNF receptor 1 protein and influences TNF sensitivity, partially protecting against TNF dependent endotoxic shock syndrome [54]. Apart from TNF- $\alpha$, it also has been documented that other pro-inflammatory cytokines such as IL-6 could increase significantly in sepsis patients [55]. Indeed, Zhou et al. reported that the down-regulation of miR-146a was associated with increased levels of IL-6 in sepsis patients [56].
A number of studies found that miRNAs could regulate inflammation through targeting toll-like receptor (TLR) signalling pathway (Figure 3). TLR mediated signalling mainly activates nuclear factor kappa B (NF$\kappa \mathrm{B})$, an important transcription factor regulating the expression of immunoregulatory and pro-inflammatory mediators [57-59]. Previous studies showed miRNAs, including miR-146a, miR-125, and miR-155, played critical roles in the negative regulation of TLR/NF- $\kappa B$ mediated innate immune and inflammatory responses [60-62]. Interestingly, transcription of primary miR155 and several other miRNAs depend on NF-кB [63]. For example, Taganov et al. reported that using LPS to stimulate human monocytic THP-1 cells could rapidly induce the expression of both miR-146a and miR-146b [64]. Notably, miR-146a can function on IRAK-1 and TRAF6 directly, which are the key adapter molecules in the TLR signalling pathway [58, 59, 65]. Additionally, miR-146a plays a vital role in vitro monocytic cell-based endotoxin tolerance $[66,67]$ and endotoxin tolerance could be revised by miR-146a inhibition [66]. Recently, Guan et al. reported that the NF- $\mathrm{KB} / \mathrm{DICER}$ signalling pathway suppressed the expression of TNF- $\alpha$ by generating mature forms of miR-125b and miR-130a that negatively regulate TNF- $\alpha$ mRNA [68]. Therefore, TLR-mediated signalling pathway is essential in sepsis [69].

With the progression of sepsis, the immune system will be reprogrammed into the immunosuppression state $[50,70]$ partly mediated by miRNAs, which can induce immune cell polarization and alter cellular immunity [71-73] (Figure 3). The upregulated expression of miR21 and miR-181b in myeloid-derived suppressor cells in septic mice precludes the differentiation of macrophages and dendritic cells through influencing the transcription factors Stat3 and $\mathrm{C} / \mathrm{EBP} \beta[72,74]$. Additionally, there is a temporal regulation in myeloid cells, with miR-155 inversely correlating with BMAL1 levels stimulated by LPS [75]. Also, other studies also proved that various miRNAs, such as mi-R210, miR-23b and miR-29a, could inhibit the expression of NF- $\kappa \mathrm{B}$ and IL-6 during sepsis via influencing different immune cells $[25,76,77]$. These studies highlight the profound integration of miRNAs in the pathophysiological of sepsis.

\section{Regulation of IncRNAs and circRNAs in sepsis}

Although a previous review demonstrated that misregulation of lncRNAs could lead to various diseases because lncRNAs were discovered in important biological and development processes [78], there have been only limited studies to evaluate the relationship between lncRNAs and sepsis. So far, several studies have indicated that the expression of IncRNAs changes in human tubular epithelial cells, cardiomyocytes and monocytes during the process of sepsis or exposure to LPS [79-81]. Furthermore, a recent study in human umbilical vein 
endothelial cells revealed that a number of lncRNAs were upregulated (with a maximum upregulation of about 70 fold), while many lncRNAs were downregulated (with a maximum downregulation of approximately 28 fold) [82]. Furthermore, Cui et al. showed that the lncRNA lnc-IL7R, which overlaps with the 3'UTR of the human interleukin-7 receptor $\alpha$-subunit gene, was significantly upregulated in LPS-treated cells and could regulate inflammatory regulation [83]. However, the role of lncRNAs in sepsis has not been fully elucidated and future research is required to investigate how IncRNAs influence sepsis and determine the exact molecular signalling pathways.

Recently, many circRNAs have been found to act as miRNAs sponges to regulate gene expression $[38,43,84]$. During the process of sepsis, miRNAs are differentially expressed inferring that some circRNAs may be involved. A recent study showed that an LPSinducible circRNA, mcircRasGEF1B, could regulate the stability of mature ICAM-1 mRNAs and might protect cells against microbial infection [85]. The experimental identification and characterization of circRNAs and their associated molecules, such as miRNAs, is required to gain an insight into the pathogenesis of sepsis and to identify novel biomarkers.

\section{NON-CODING RNAS AS POTENTIAL BIOMARKERS IN SEPSIS}

\section{Limitations of present biomarkers}

According to the National Institute of Health, a biomarker is a "characteristic that can be objectively measured and evaluated as an indicator of normal biological processes, pathological processes, or pharmacological responses to a therapeutic intervention" [86]. Although microbiological culture is the gold standard in distinguishing sepsis from other diseases [3, 87], this method is time-consuming and often associated with false negative results. Additionally, CRP is another common parameter but it can also increase after burns and cannot differentiate between infected and non-infected burn patients [88]. CRP lacks specificity, and concentrations may be increased in other inflammatory and all infectious disorders [12]. Low levels of CRP should be interpreted

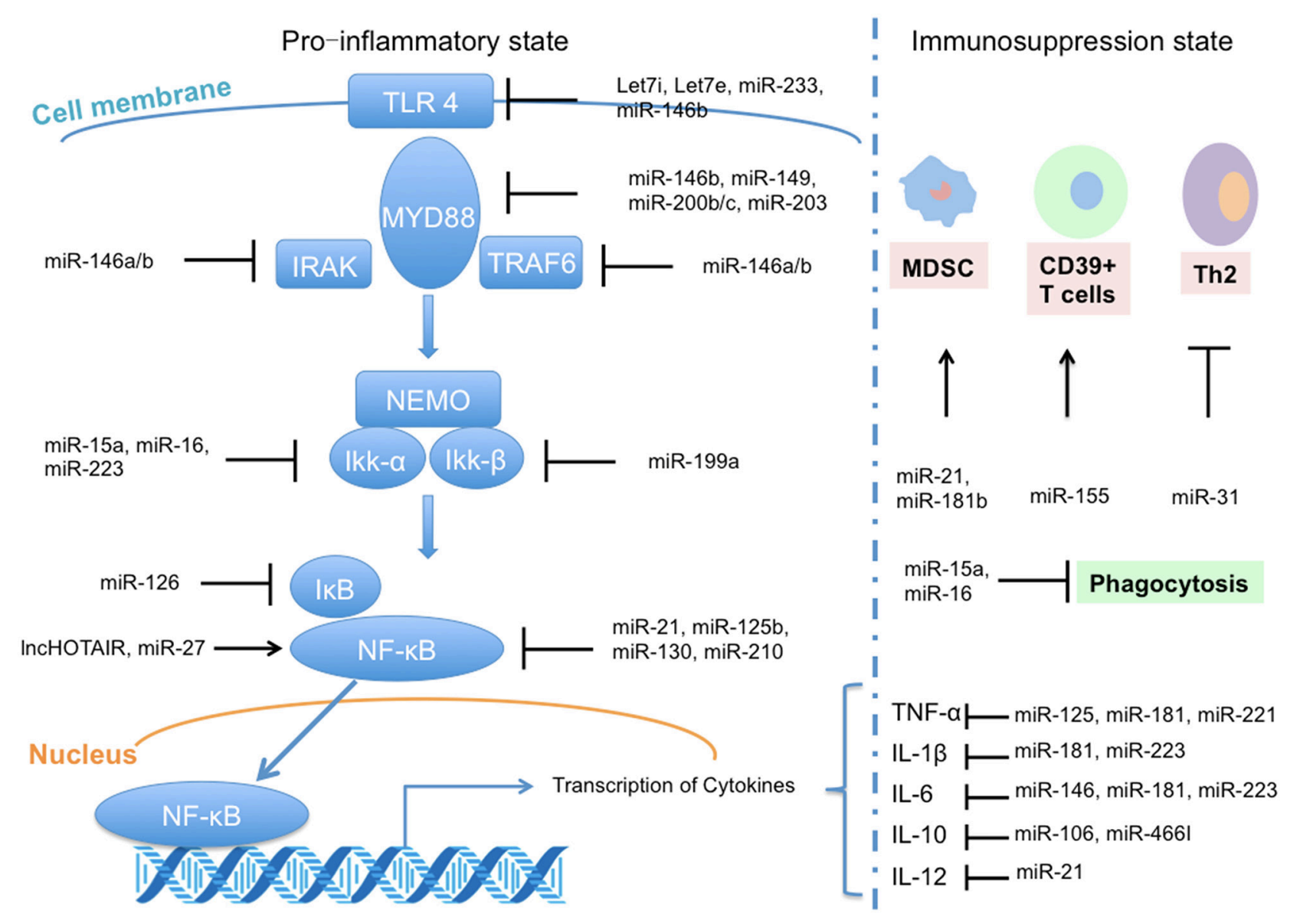

Figure 3: Regulation of microRNA (miRNA) and long non-coding RNA (IncRNA) in sepsis, including interacting with toll-like receptor 4 (TLR4) signal pathway in pro-inflammatory state and regulation functions in immunosuppression state (based on [14]). 
with caution in patients with fulminant hepatic failure, because these may reflect severity of hepatic synthetic function rather than sepsis or inflammation [89]. Furthermore, PCT is a pro-hormone of calcitonin and may be released from tissues and cells during infection [90]. The guidelines suggest that measurement of PCT levels can be used to support shortening the duration of antimicrobial therapy in septic patients [3]. Although a meta-analysis showed that PCT might be useful to guide antibiotic therapy in septic patients [91], recent studies demonstrated that PCT-guidance therapy did not affect the frequency of diagnostic or therapeutic procedures $[3,92]$. Besides, there is no single cut-off range of PCT levels for defining sepsis. The optimum cut-off ranges for PCT depend on many factors such as the clinical settings, site and extent of infection, and co-morbidities [12]. IL-6 is a biomarker in septic patients [93, 94], however, IL-6 levels are also upregulated in other non-infectious diseases $[95,96]$. Of note, organ dysfunction often occurs during the process of sepsis such as sepsis-induced cardiac dysfunction and sepsis-associated pulmonary injury. Therefore, considering the limitations of the current biomarkers, it is necessary to develop novel biomarkers, especially those that can represent the specific organ dysfunction.

\section{Potential biomarkers for sepsis}

Non-coding RNAs have been detected in different tissues or organs suggesting that they may be potential biomarkers for sepsis and sepsis-related organ dysfunction (Supplementary Tables 1 [79-83, 97-100] and 2 [18, 21, $22,73,85,101-120])$. Nowadays, the clinical sample which is suitable for detect non-coding RNAs is blood from patients, including serum, plasma, and blood leucocytes. Extracellular miRNAs exit in blood which could be quantified rapidly in a clinical setting, unlike microbial cultures that are time consuming [24]. Such property makes it possible to use miRNAs as biomarkers for the diagnosis of sepsis in clinic. As highlighted, different miRNAs are differentially expressed in sepsis. For example, studies showed that miR-16, miR122, and miR133a are increased in serum of septic patients [21, $106,121]$, whereas the expression of some miRNAs, such as miR-25 and miR-181b is decreased [107, 116]. In addition, a recent study reported that the clinical accuracy of miRNA-25 for sepsis diagnosis was better than CRP and PCT (area under ROC curve $=0.806,0.676$ and 0.726, for miRNA-25, CRP and PCT, respectively) [107]. The decrease in level of miRNA-25 was correlated with the severity of sepsis, SOFA score, CRP and PCT level [107]. Furthermore, a similar study showed that a cut-off point set at -1.89 , miR-233 yielded a specificity of $100 \%$ and a sensitivity of $80 \%$, while at a cut-off point set at -2.98 , miR-146a yielded a specificity of $100 \%$ and a sensitivity of $63.3 \%$ [119]. These two miRNAs might serve as new biomarkers for sepsis with high specificity and sensitivity [119]. Additionally, miRNAs were reported to be related with prognosis in patients with sepsis. The study conducted by Vasilescu et al found that miR-150 levels were significantly reduced in plasma samples of sepsis patients and correlated with the level of disease severity measured by the SOFA scores [120]. MiR-150 was found to control c-Myb expression in vivo in a dose-dependent manner over a narrow range of miRNA and c-Myb concentrations, and this dramatically affected lymphocyte development and response [122], which could strengthen the functional significance of miR-150 downregulation in sepsis patients. Besides, the study conducted by Wang et al showed that a combination of sepsis stage, SOFA scores, and miR-574-5p could provide $78.13 \%$ sensitivity and $91.84 \%$ specificity of predictive capability for the death of septic patients [123]. Therefore, miRNAs could play a critical role in diagnosis and predictive capability for prognosis of sepsis.

\section{Potential biomarkers reflecting sepsis-induced cardiac dysfunction in sepsis}

Sepsis-induced cardiac dysfunction is characterized by impaired myocardial contractility and reduced ejection fraction [124]. However, the pathophysiology of sepsisinduced myocardial dysfunction is unclear and there is currently no specific drug to reverse sepsis-induced myocardial dysfunction [125]. Several studies have showed that miRNAs have a potential role in sepsisinduced cardiac dysfunction. For example, miR-233 could be repressed and therefore generate an inflammatory response at multiple levels, subsequently inducing myocardial depression in a severe septic mouse model [109]. Additionally, Wang et al. showed that inhibition of miR-155 protected against LPS-induced cardiac dysfunction [101]. Furthermore, miR-146a can attenuate sepsis-induced cardiac dysfunction by preventing NF$\kappa \mathrm{B}$ activation and reduce inflammatory cell infiltration [57]. A recent study showed that LPS could inhibit miR499 expression, which leads to cardiomyocyte apoptosis through the Bcl-2 family apoptotic pathway [103]. Except miRNAs, lncRNA also has been proved to be involved in the process of sepsis-induced cardiac dysfunction. In cardiomyocytes from septic mice, the lncRNA HOTAIR was found to be significantly upregulated and had a positive regulation on p65 phosphorylation and NF-kB activation [79]. Therefore, several non-coding RNAs have been identified that potentially mediate sepsis-induced cardiac dysfunction. These new non-coding RNAs may be novel diagnostic circulating biomarkers and have the potential to be developed into new intervention targets for patients prone to develop sepsis-induced cardiac dysfunction. 


\section{Potential biomarkers representing sepsis- induced pulmonary injury}

A previous review demonstrated that the treatment of underlying sepsis and identification of patients at risk of acute respiratory distress syndrome (ARDS) is of great importance in septic patients [126]. At present, there are no specific diagnostic biomarkers for sepsisinduced ARDS. MiRNAs may be involved in regulating sepsis-induced pulmonary injury, for example, Ying et al. showed that MiR-127 modulated macrophage polarization and promoted lung inflammation and injury by activating the JNK pathway [18], suggesting that miRNAs may be involved in sepsis-induced pulmonary injury. However, few studies have investigated the association between sepsis-induced pulmonary injury and non-coding. Further studies are needed to detect how non-coding RNAs influence pulmonary injury and to determine the regulatory mechanisms involved.

\section{Potential biomarkers regarding to sepsis- associated coagulopathy and endothelial dysfunction}

Thrombocytopenia has become one of the most common abnormalities in patients with severe sepsis $[127,128]$. A recent study showed that septic patients with thrombocytopenia had increased plasma and miRNAs expression levels of IL-18 and decreased expression of miR-130a, suggesting that miRNAs were involved in the pathophysiology of sepsis-associated thrombocytopenia and hence, a potential biomarker [102]. In addition, a clinical trial conducted by Wang et al. demonstrated that miR-122 levels were significantly higher in patients of the abnormal coagulation group than the normal coagulation group [121]. However, it is still unknown how the miRNAs affect coagulation and further studies are warranted to identify more miRNAs as biomarkers for coagulopathy.

Endothelial inflammation plays a critical role in the pathogenesis of sepsis [129]. A study discovered that LPSinduced endothelial dysfunction was mediated through the Slit2-Robo4 pathway and downregulation of Slit2 reduced the expression of miR-218 [110]. Moreover, miR-147b was involved in endothelial protection through degrading ADAM15 (a mediator regulating endothelial permeability) mRNA [111]. Taken together, this suggests that various miRNAs might be involved and could be novel biomarkers for sepsis-associated endothelial dysfunction.

\section{Potential biomarkers for sepsis-associated liver dysfunction or kidney dysfunction}

A growing body of evidence has proved that miRNAs and/or lncRNAs participate in liver and kidney dysfunction during sepsis. For example, the expression of miR-142-3 increased in a rat cecal ligation and puncture model, thereby reducing adenylyl cyclase 9 expression in liver macrophages [130]. Similarly, the expression of miR-122 was upregulated in liver injury [108, 118]. Jia et al. also showed that knockdown of miR-21 upregulated its target effectors programmed cell death protein 4 and phosphatase and tensin homolog deleted on chromosome 10 expression, resulting in an increase in apoptosis and exacerbated LPS-induced acute kidney injury [105]. Notably, sequencing of RNA extracted from exposure of human proximal tubular epithelial cells to the plasma of critically ill septic patients demonstrated that a lncRNA, linc-ATP13A4-8, was significantly upregulated on exposure to plasma of septic patients [80]. Nonetheless, more research is required to explore organ-specific non-coding RNAs in liver or kidney and evaluate their credibility and validity as biomarkers for sepsis.

\section{PROMISE AND CHALLENGE IN USING NON-CODING RNAS AS BIOMARKERS AND THERAPEUTIC TARGETS}

Increasing evidence suggests that non-coding RNAs play important roles in the regulation of pathophysiological processes of sepsis and sepsisassociated organ dysfunction, therefore they may be novel biomarkers and therapeutic targets [14]. However, their clinical application has not been evaluated and may encounter many challenges.

Firstly, non-coding RNAs as biomarkers is in its infancy. Although studies investigating the relationship between non-coding RNAs and sepsis have used RTPCR and next-generation sequencing and microarray analyses $[115,131,132]$, most studies regarding noncoding RNA in sepsis are only at the experimental stage. Notably, it is common to report sensitivity, specificity and associated area under the curve between miRNAs and sepsis [107, 119, 123, 133], but no studies have assessed the feasibility of selecting lncRNA/circRNA as novel biomarkers. Furthermore, the evaluation of the aforementioned association has only been performed in a relatively small number of studies, so reporting bias may exist due to differences in the area, population and race among studies. Large-scale clinical trials are warranted to identify more precise non-coding RNAs biomarkers for sepsis. Additionally, numerous studies have detected non-coding RNAs representing sepsis, but highly specific biomarkers for sepsis-associated organ dysfunction, such as sepsis-induced pulmonary injury, are relatively limited. The development of tissue-specific or organ-specific biomarkers would be helpful for the early treatment and intervention of organ failure, which may improve the survival rate of sepsis. Clearly, genome-wide profiling of miRNAs expression distinguished septic from nonseptic patients. Nonetheless, prediction of the likelihood of a non-septic patient developing sepsis may be more clinically relevant to reduce mortality and morbidity in 
critical care units [14]. Additionally, as sepsis and septic shock are clinical emergency, further studies should detect whether non-coding RNAs could be used as biomarkers for early diagnosis and early prognosis of the diseases, and also compare economical aspect of non-coding RNAs with other methods.

Secondly, although many studies using cell and animal models have showed that miRNAs modulators be used in the fight against sepsis, considerable challenges must be overcome in order to successfully translate these approaches into clinical practice. Recent studies demonstrated that antisense miRNA inhibitors could be used to improve specific diseases in animal models and could offer novel therapeutic targets [134, 135]. AntimiRNAs have been proved safe and already successful in clinical phase 2 studies [136]for the treatment of liver disease. The evaluation of the feasibility of miRNAs as septic therapy predominantly employs two approaches, use of antagomir or miRNA mimics [14]. However, sepsis and septic shock are different from some chronic diseases, because they are the medical emergencies. Therefore, the first challenge and problem to be considered is their delivery route. Besides, the expression of some miRNAs is organspecific, so, further studies should focus on how to target specific organs without influencing others. According the latest guidelines [3], treatment often requires different types of medication at the same time. Therefore, the interaction between anti-miRNAs and such medications is also required for the management of septic patients. Moreover, with respect to clinical trials, there are striking inter-study variances of miRNA-regulation patterns in different cohorts of sepsis patients, which are most likely due to a lack in standardization in the sample collection, data normalization and analysis [25]. Therefore, a consensus on the optimal normalization strategy for miRNAs analysis from serum is required for more precise results.

Thirdly, the investigation of IncRNA/circRNA in sepsis may reveal the molecular mechanisms of sepsis. However, lncRNAs and circRNAs can exhibit diverse functions, for example, lncRNAs can regulate chromatin state through cis-regulation or trans-regulation, act as molecular scaffolds to organize protein complexes [36] and function as miRNA sponges to influence the action of miRNAs. Furthermore, some lncRNAs may act through more than one mechanism of action. Although limited molecular mechanistic studies have proved lncRNA/ circRNA are involved in sepsis, it is unclear how lncRNA/ circRNA influence the process of sepsis. Further studies could determine whether lncRNA/circRNA are organspecific, potentially identifying new biomarkers and therapeutic targets.

As highlighted, if the above problems and challenges can be overcome, non-coding RNAs are attractive "next generation" biomarkers. With the in-depth understanding of the mechanism of sepsis, non-coding RNAs could also become the novel therapeutic targets in the future.

\section{CONCLUSIONS}

In conclusion, increasing evidence has proved that non-coding RNAs are involved in the regulation of the pathophysiological process of sepsis. Although there are many problems and challenges regarding the application of non-coding RNAs clinical practice to be addressed, they have the potential to be new biomarkers and novel therapeutic targets for sepsis and septic shock. It is essential to further explore tissue- or organ-specific noncoding RNAs that might be more meaningful for targeted therapy of sepsis. In addition, future research should also focus on elucidating their molecular mechanisms, to further our understanding of the disease process. Noncoding RNAs may provide a new insight into sepsis and the development of mediators of non-coding RNAs may have a promising future.

\section{Abbreviations}

ARDS, acute respiratory distress syndrome; circRNAs, circular RNAs; CRP, C-reaction protein; DGCR, DiGeorge Syndrome Critical Region 8; IL6, interleukin-6; lncRNAs, long non-coding RNAs; LPS, lipopolysaccharide; miRNAs, microRNAs; PCT, procalcitonin; RISC, RNA-induced silencing complex; TLR, toll-like receptor; TNF- $\alpha$, tumor necrosis factor- $\alpha$.

\section{Author contributions}

All authors participated in drafting or revising of the manuscript, and approved the final manuscript. C-FL had primary responsibility for final content.

\section{ACKNOWLEDGMENTS}

We are grateful to Yuan Zhang (Department of Emergency, Shengjing Hospital of China Medical University, Shenyang, China) for checking the content of tables.

\section{CONFLICTS OF INTEREST}

The authors declare no conflicts of interest.

\section{FUNDING}

This study was supported by the National Natural Science Foundation of China (No. 81372039 for ChunFeng Liu, No. 81602918 for Qi- Jun Wu and No. 81402130 for $\mathrm{Da} \mathrm{Li}$ ), the Science and Technology Foundation of Shenyang (No. F13-220-9-38 for Chun-Feng Liu), the Doctoral Start-up Foundation of Liaoning Province (No. 201501007 for Qi-Jun Wu and No. 20141045 for Da Li), and the Fok Ying Tung Education Foundation (No. 151039 for $\mathrm{Da} \mathrm{Li}$ ). 


\section{REFERENCES}

1. Singer M, Deutschman CS, Seymour CW, Shankar-Hari M, Annane D, Bauer M, Bellomo R, Bernard GR, Chiche JD, Coopersmith CM, Hotchkiss RS, Levy MM, Marshall JC, et al. The Third International Consensus Definitions for Sepsis and Septic Shock (Sepsis-3). JAMA. 2016; 315:801-810.

2. Angus DC, van der Poll T. Severe sepsis and septic shock. N Engl J Med. 2013; 369:2063.

3. Rhodes A, Evans LE, Alhazzani W, Levy MM, Antonelli M, Ferrer R, Kumar A, Sevransky JE, Sprung CL, Nunnally ME, Rochwerg B, Rubenfeld GD, Angus DC, et al. Surviving Sepsis Campaign: International Guidelines for Management of Sepsis and Septic Shock: 2016. Intensive Care Med. 2017; 43:304-377.

4. Angus DC, Linde-Zwirble WT, Lidicker J, Clermont G, Carcillo J, Pinsky MR. Epidemiology of severe sepsis in the United States: analysis of incidence, outcome, and associated costs of care. Crit Care Med. 2001; 29:1303-1310.

5. Gaieski DF, Edwards JM, Kallan MJ, Carr BG. Benchmarking the incidence and mortality of severe sepsis in the United States. Crit Care Med. 2013; 41:1167-1174.

6. Iwashyna TJ, Cooke CR, Wunsch H, Kahn JM. Population burden of long-term survivorship after severe sepsis in older Americans. J Am Geriatr Soc. 2012; 60:1070-1077.

7. Zhou J, Tian H, Du X, Xi X, An Y, Duan M, Weng L, Du B. Population-Based Epidemiology of Sepsis in a Subdistrict of Beijing. Crit Care Med. 2017; 45:1168-1176.

8. Martin GS, Mannino DM, Eaton S, Moss M. The epidemiology of sepsis in the United States from 1979 through 2000. N Engl J Med. 2003; 348:1546-1554.

9. Iwashyna TJ, Ely EW, Smith DM, Langa KM. Long-term cognitive impairment and functional disability among survivors of severe sepsis. JAMA. 2010; 304:1787-1794.

10. Bloos F, Reinhart K. Rapid diagnosis of sepsis. Virulence. 2014; 5:154-160.

11. Pierrakos C, Vincent JL. Sepsis biomarkers: a review. Crit Care. 2010; 14:R15.

12. Sankar V, Webster NR. Clinical application of sepsis biomarkers. J Anesth. 2013; 27:269-283.

13. Xiao W, Mindrinos MN, Seok J, Cuschieri J, Cuenca AG, Gao H, Hayden DL, Hennessy L, Moore EE, Minei JP, Bankey PE, Johnson JL, Sperry J, et al. A genomic storm in critically injured humans. J Exp Med. 2011; 208:2581-2590.

14. Ho J, Chan H, Wong SH, Wang MH, Yu J, Xiao Z, Liu X, Choi G, Leung CC, Wong WT, Li Z, Gin T, Chan MT, et al. The involvement of regulatory non-coding RNAs in sepsis: a systematic review. Crit Care. 2016; 20:383.

15. Holdt LM, Stahringer A, Sass K, Pichler G, Kulak NA, Wilfert W, Kohlmaier A, Herbst A, Northoff BH, Nicolaou A, Gabel G, Beutner F, Scholz M, et al. Circular non-coding RNA ANRIL modulates ribosomal RNA maturation and atherosclerosis in humans. Nat Commun. 2016; 7:12429.
16. Wang K, Long B, Liu F, Wang JX, Liu CY, Zhao B, Zhou LY, Sun T, Wang M, Yu T, Gong Y, Liu J, Dong YH, et al. A circular RNA protects the heart from pathological hypertrophy and heart failure by targeting miR-223. Eur Heart J. 2016; 37:2602-2611.

17. Liu F, Li Y, Jiang R, Nie C, Zeng Z, Zhao N, Huang C, Shao Q, Ding C, Qing C, Xia L, Zeng E, Qian K. miR132 inhibits lipopolysaccharide-induced inflammation in alveolar macrophages by the cholinergic anti-inflammatory pathway. Exp Lung Res. 2015; 41:261-269.

18. Ying H, Kang Y, Zhang H, Zhao D, Xia J, Lu Z, Wang H, $\mathrm{Xu}$ F, Shi L. MiR-127 modulates macrophage polarization and promotes lung inflammation and injury by activating the JNK pathway. J Immunol. 2015; 194:1239-1251.

19. Brudecki L, Ferguson DA, McCall CE, El Gazzar M. MicroRNA-146a and RBM4 form a negative feed-forward loop that disrupts cytokine mRNA translation following TLR4 responses in human THP-1 monocytes. Immunol Cell Biol. 2013; 91:532-540.

20. Precone V, Stornaiuolo G, Amato A, Brancaccio G, Nardiello S, Gaeta GB. Different changes in mitochondrial apoptotic pathway in lymphocytes and granulocytes in cirrhotic patients with sepsis. Liver Int. 2013; 33:834-842.

21. Tacke F, Roderburg C, Benz F, Cardenas DV, Luedde M, Hippe HJ, Frey N, Vucur M, Gautheron J, Koch A, Trautwein C, Luedde T. Levels of circulating miR-133a are elevated in sepsis and predict mortality in critically ill patients. Crit Care Med. 2014; 42:1096-1104.

22. Roderburg C, Luedde M, Vargas CD, Vucur M, Scholten D, Frey N, Koch A, Trautwein C, Tacke F, Luedde T. Circulating microRNA-150 serum levels predict survival in patients with critical illness and sepsis. PLoS One. 2013; 8:e54612.

23. Krol J, Loedige I, Filipowicz W. The widespread regulation of microRNA biogenesis, function and decay. Nat Rev Genet. 2010; 11:597-610.

24. Essandoh K, Fan GC. Role of extracellular and intracellular microRNAs in sepsis. Biochim Biophys Acta. 2014; 1842:2155-2162.

25. Benz F, Roy S, Trautwein C, Roderburg C, Luedde T. Circulating MicroRNAs as Biomarkers for Sepsis. Int J Mol Sci. 2016; 17.

26. Lee Y, Ahn C, Han J, Choi H, Kim J, Yim J, Lee J, Provost P, Radmark O, Kim S, Kim VN. The nuclear RNase III Drosha initiates microRNA processing. Nature. 2003; 425:415-419.

27. Lund E, Guttinger S, Calado A, Dahlberg JE, Kutay U. Nuclear export of microRNA precursors. Science. 2004; 303:95-98.

28. Ha M, Kim VN. Regulation of microRNA biogenesis. Nat Rev Mol Cell Biol. 2014; 15:509-524.

29. Macfarlane LA, Murphy PR. MicroRNA: Biogenesis, Function and Role in Cancer. Curr Genomics. 2010; 11:537-561. 
30. Zhang Q, Su J, Wang Z, Qi H, Ge Z, Li Z, Chen WD, Wang YD. MicroRNA-149 suppresses hepatic inflammatory response through antagonizing STAT3 signaling pathway. Oncotarget. 2017; 8:65397-65406. https://doi.org/10.18632/ oncotarget.18541.

31. Li S, Lee C, Song J, Lu C, Liu J, Cui Y, Liang H, Cao C, Zhang F, Chen H. Circulating microRNAs as potential biomarkers for coronary plaque rupture. Oncotarget. 2017; 8:48145-48156. https://doi.org/10.18632/oncotarget.18308.

32. Mercer TR, Dinger ME, Mattick JS. Long non-coding RNAs: insights into functions. Nat Rev Genet. 2009; 10:155-159.

33. Volders PJ, Verheggen K, Menschaert G, Vandepoele K, Martens L, Vandesompele J, Mestdagh P. An update on LNCipedia: a database for annotated human lncRNA sequences. Nucleic Acids Res. 2015; 43:4363-4364.

34. Volders PJ, Helsens K, Wang X, Menten B, Martens L, Gevaert K, Vandesompele J, Mestdagh P. LNCipedia: a database for annotated human lncRNA transcript sequences and structures. Nucleic Acids Res. 2013; 41:D246-D251.

35. Johnsson P, Lipovich L, Grander D, Morris KV. Evolutionary conservation of long non-coding RNAs; sequence, structure, function. Biochim Biophys Acta. 2014; 1840:1063-1071.

36. Boon RA, Jae N, Holdt L, Dimmeler S. Long Noncoding RNAs: From Clinical Genetics to Therapeutic Targets? J Am Coll Cardiol. 2016; 67:1214-1226.

37. Jeck WR, Sorrentino JA, Wang K, Slevin MK, Burd CE, Liu J, Marzluff WF, Sharpless NE. Circular RNAs are abundant, conserved, and associated with ALU repeats. RNA. 2013; 19:141-157.

38. Memczak S, Jens M, Elefsinioti A, Torti F, Krueger J, Rybak A, Maier L, Mackowiak SD, Gregersen LH, Munschauer M, Loewer A, Ziebold U, Landthaler M, et al. Circular RNAs are a large class of animal RNAs with regulatory potency. Nature. 2013; 495:333-338.

39. Hu G, Dong B, Zhang J, Zhai W, Xie T, Huang B, Huang C, Yao X, Zheng J, Che J, Xu YF. The long noncoding RNA HOTAIR activates the Hippo pathway by directly binding to SAV1 in renal cell carcinoma. Oncotarget. 2017; 8:5865458667. https://doi.org/10.18632/oncotarget.17414.

40. Fan R, Cao C, Zhao X, Shi Q, Zhao J, Xu S. Downregulated long noncoding RNA ALDBGALG031276R15049 induces inflammation in chicken muscle suffered from selenium deficiency by regulating stearoyl-CoA desaturase. Oncotarget. 2017; 8:52761-52774. https://doi.org/10.18632/ oncotarget. 17187.

41. Jeck WR, Sharpless NE. Detecting and characterizing circular RNAs. Nat Biotechnol. 2014; 32:453-461.

42. Salzman J, Gawad C, Wang PL, Lacayo N, Brown PO. Circular RNAs are the predominant transcript isoform from hundreds of human genes in diverse cell types. PLoS One. 2012; 7:e30733.
43. Zheng Q, Bao C, Guo W, Li S, Chen J, Chen B, Luo Y, Lyu D, Li Y, Shi G, Liang L, Gu J, He X, et al. Circular RNA profiling reveals an abundant circHIPK3 that regulates cell growth by sponging multiple miRNAs. Nat Commun. 2016; $7: 11215$.

44. Li Z, Huang C, Bao C, Chen L, Lin M, Wang X, Zhong G, Yu B, Hu W, Dai L, Zhu P, Chang Z, Wu Q, et al. Exonintron circular RNAs regulate transcription in the nucleus. Nat Struct Mol Biol. 2015; 22:256-264.

45. Conn SJ, Pillman KA, Toubia J, Conn VM, Salmanidis M, Phillips CA, Roslan S, Schreiber AW, Gregory PA, Goodall GJ. The RNA binding protein quaking regulates formation of circRNAs. Cell. 2015; 160:1125-1134.

46. Ashwal-Fluss R, Meyer M, Pamudurti NR, Ivanov A, Bartok O, Hanan M, Evantal N, Memczak S, Rajewsky N, Kadener S. circRNA biogenesis competes with pre-mRNA splicing. Mol Cell. 2014; 56:55-66.

47. O'Connell RM, Rao DS, Baltimore D. microRNA regulation of inflammatory responses. Annu Rev Immunol. 2012; 30:295-312.

48. O’Connell RM, Kahn D, Gibson WS, Round JL, Scholz RL, Chaudhuri AA, Kahn ME, Rao DS, Baltimore D. MicroRNA-155 promotes autoimmune inflammation by enhancing inflammatory $\mathrm{T}$ cell development. Immunity. 2010; 33:607-619.

49. Xiao C, Rajewsky K. MicroRNA control in the immune system: basic principles. Cell. 2009; 136:26-36.

50. Gentile LF, Cuenca AG, Efron PA, Ang D, Bihorac A, McKinley BA, Moldawer LL, Moore FA. Persistent inflammation and immunosuppression: a common syndrome and new horizon for surgical intensive care. $\mathrm{J}$ Trauma Acute Care Surg. 2012; 72:1491-1501.

51. Delano MJ, Scumpia PO, Weinstein JS, Coco D, Nagaraj S, Kelly-Scumpia KM, O’Malley KA, Wynn JL, Antonenko S, Al-Quran SZ, Swan R, Chung CS, Atkinson MA, et al. MyD88-dependent expansion of an immature GR-1(+) $\mathrm{CD} 11 \mathrm{~b}(+)$ population induces $\mathrm{T}$ cell suppression and $\mathrm{Th} 2$ polarization in sepsis. J Exp Med. 2007; 204:1463-1474.

52. Dan C, Jinjun B, Zi-Chun H, Lin M, Wei C, Xu Z, Ri Z, Shun C, Wen-Zhu S, Qing-Cai J, Wu Y. Modulation of TNF-alpha mRNA stability by human antigen $\mathrm{R}$ and miR181s in sepsis-induced immunoparalysis. EMBO Mol Med. 2015; 7:140-157.

53. Huang HC, Yu HR, Huang LT, Huang HC, Chen RF, Lin IC, Ou CY, Hsu TY, Yang KD. miRNA-125b regulates TNFalpha production in CD14+ neonatal monocytes via posttranscriptional regulation. J Leukoc Biol. 2012; 92:171-182.

54. Puimege L, Van Hauwermeiren F, Steeland S, Van Ryckeghem S, Vandewalle J, Lodens S, Dejager L, Vandevyver S, Staelens J, Timmermans S, Vandenbroucke RE, Libert C. Glucocorticoid-induced microRNA-511 protects against TNF by down-regulating TNFR1. EMBO Mol Med. 2015; 7:1004-1017. 
55. Mera S, Tatulescu D, Cismaru C, Bondor C, Slavcovici A, Zanc V, Carstina D, Oltean M. Multiplex cytokine profiling in patients with sepsis. APMIS. 2011; 119:155-163.

56. Zhou J, Chaudhry H, Zhong Y, Ali MM, Perkins LA, Owens WB, Morales JE, McGuire FR, Zumbrun EE, Zhang J, Nagarkatti PS, Nagarkatti M. Dysregulation in microRNA expression in peripheral blood mononuclear cells of sepsis patients is associated with immunopathology. Cytokine. 2015; 71:89-100.

57. Gao M, Wang X, Zhang X, Ha T, Ma H, Liu L, Kalbfleisch JH, Gao X, Kao RL, Williams DL, Li C. Attenuation of Cardiac Dysfunction in Polymicrobial Sepsis by MicroRNA-146a Is Mediated via Targeting of IRAK1 and TRAF6 Expression. J Immunol. 2015; 195:672-682.

58. Zhang G, Ghosh S. Toll-like receptor-mediated NF-kappaB activation: a phylogenetically conserved paradigm in innate immunity. J Clin Invest. 2001; 107:13-19.

59. Medzhitov R, Preston-Hurlburt P, Janeway CJ. A human homologue of the Drosophila Toll protein signals activation of adaptive immunity. Nature. 1997; 388:394-397.

60. O'Neill LA, Sheedy FJ, McCoy CE. MicroRNAs: the finetuners of Toll-like receptor signalling. Nat Rev Immunol. 2011; 11:163-175.

61. Quinn SR, O'Neill LA. A trio of microRNAs that control Toll-like receptor signalling. Int Immunol. 2011; 23:421-425

62. O'Connell RM, Rao DS, Chaudhuri AA, Baltimore D. Physiological and pathological roles for microRNAs in the immune system. Nat Rev Immunol. 2010; 10:111-122.

63. Monk CE, Hutvagner G, Arthur JS. Regulation of miRNA transcription in macrophages in response to Candida albicans. PLoS One. 2010; 5:e13669.

64. Taganov KD, Boldin MP, Chang KJ, Baltimore D. NF-kappaB-dependent induction of microRNA miR146, an inhibitor targeted to signaling proteins of innate immune responses. Proc Natl Acad Sci U S A. 2006; 103:12481-12486.

65. Quinn EM, Wang JH, O'Callaghan G, Redmond HP. MicroRNA-146a is upregulated by and negatively regulates TLR2 signaling. PLoS One. 2013; 8:e62232.

66. El GM, Church A, Liu T, McCall CE. MicroRNA-146a regulates both transcription silencing and translation disruption of TNF-alpha during TLR4-induced gene reprogramming. J Leukoc Biol. 2011; 90:509-519.

67. Nahid MA, Satoh M, Chan EK. MicroRNA in TLR signaling and endotoxin tolerance. Cell Mol Immunol. 2011; 8:388-403.

68. Guan Y, Yao H, Wang J, Sun K, Cao L, Wang Y. NF-kappaB-DICER-miRs Axis Regulates TNF-alpha Expression in Responses to Endotoxin Stress. Int J Biol Sci. $2015 ; 11: 1257-1268$.

69. Williams DL, Ha T, Li C, Kalbfleisch JH, Schweitzer J, Vogt W, Browder IW. Modulation of tissue Toll-like receptor 2 and 4 during the early phases of polymicrobial sepsis correlates with mortality. Crit Care Med. 2003; 31:1808-1818.

70. Ho J, Yu J, Wong SH, Zhang L, Liu X, Wong WT, Leung CC, Choi G, Wang MH, Gin T, Chan MT, Wu WK. Autophagy in sepsis: Degradation into exhaustion? Autophagy. 2016; 12:1073-1082.

71. Liu J, Shi K, Chen M, Xu L, Hong J, Hu B, Yang X, Sun R. Elevated miR-155 expression induces immunosuppression via CD39(+) regulatory T-cells in sepsis patient. Int J Infect Dis. 2015; 40:135-141.

72. McClure C, Brudecki L, Ferguson DA, Yao ZQ, Moorman JP, McCall CE, El Gazzar M. MicroRNA 21 (miR-21) and miR-181b couple with NFI-A to generate myeloid-derived suppressor cells and promote immunosuppression in late sepsis. Infect Immun. 2014; 82:3816-3825.

73. Li Y, Dalli J, Chiang N, Baron RM, Quintana C, Serhan $\mathrm{CN}$. Plasticity of leukocytic exudates in resolving acute inflammation is regulated by MicroRNA and proresolving mediators. Immunity. 2013; 39:885-898.

74. McClure C, McPeak MB, Youssef D, Yao ZQ, McCall CE, El GM. Stat3 and C/EBPbeta synergize to induce miR-21 and miR-181b expression during sepsis. Immunol Cell Biol. 2017; 95:42-55.

75. Curtis AM, Fagundes CT, Yang G, Palsson-McDermott EM, Wochal P, McGettrick AF, Foley NH, Early JO, Chen L, Zhang H, Xue C, Geiger SS, Hokamp K, et al. Circadian control of innate immunity in macrophages by miR-155 targeting Bmal1. Proc Natl Acad Sci U S A. 2015; 112:7231-7236.

76. Song X, Wang CT, Geng XH. MicroRNA-29a promotes apoptosis of monocytes by targeting STAT3 during sepsis. Genet Mol Res. 2015; 14:13746-13753.

77. Qi J, Qiao Y, Wang P, Li S, Zhao W, Gao C. microRNA-210 negatively regulates LPS-induced production of proinflammatory cytokines by targeting NF-kappaB1 in murine macrophages. FEBS Lett. 2012; 586:1201-1207.

78. Dey BK, Mueller AC, Dutta A. Long non-coding RNAs as emerging regulators of differentiation, development, and disease. Transcription. 2014; 5:e944014.

79. Wu H, Liu J, Li W, Liu G, Li Z. LncRNA-HOTAIR promotes TNF-alpha production in cardiomyocytes of LPSinduced sepsis mice by activating NF-kappaB pathway. Biochem Biophys Res Commun. 2016; 471:240-246.

80. Lin J, Zhang X, Xue C, Zhang H, Shashaty MG, Gosai SJ, Meyer N, Grazioli A, Hinkle C, Caughey J, Li W, Susztak $\mathrm{K}$, Gregory BD, et al. The long noncoding RNA landscape in hypoxic and inflammatory renal epithelial injury. Am J Physiol Renal Physiol. 2015; 309:F901-F913.

81. Liu Y, Ferguson JF, Xue C, Ballantyne RL, Silverman IM, Gosai SJ, Serfecz J, Morley MP, Gregory BD, Li M, Reilly MP. Tissue-specific RNA-Seq in human evoked inflammation identifies blood and adipose LincRNA signatures of cardiometabolic diseases. Arterioscler Thromb Vasc Biol. 2014; 34:902-912. 
82. Singh KK, Matkar PN, Muhammad S, Quan A, Gupta V, Teoh H, Al-Omran M, Verma S. Investigation of novel LPSinduced differentially expressed long non-coding RNAs in endothelial cells. Mol Cell Biochem. 2016; 421:157-168.

83. Cui H, Xie N, Tan Z, Banerjee S, Thannickal VJ, Abraham E, Liu G. The human long noncoding RNA lnc-IL7R regulates the inflammatory response. Eur J Immunol. 2014; 44:2085-2095.

84. Hansen TB, Jensen TI, Clausen BH, Bramsen JB, Finsen B, Damgaard CK, Kjems J. Natural RNA circles function as efficient microRNA sponges. Nature. 2013; 495:384-388.

85. Ng WL, Marinov GK, Liau ES, Lam YL, Lim YY, Ea CK. Inducible RasGEF1B circular RNA is a positive regulator of ICAM-1 in the TLR4/LPS pathway. RNA Biol. 2016; 13:861-871.

86. Biomarkers Definition Working Group. Biomarkers and surrogate endpoints: preferred definitions and conceptual framework. Clin Pharmacol Ther. 2001; 69:89-95.

87. Vincent JL. Management of sepsis in the critically ill patient: key aspects. Expert Opin Pharmacother. 2006; 7:2037-2045.

88. Barati M, Alinejad F, Bahar MA, Tabrisi MS, Shamshiri AR, Bodouhi NO, Karimi H. Comparison of WBC, ESR, CRP and PCT serum levels in septic and non-septic burn cases. Burns. 2008; 34:770-774.

89. Silvestre JP, Coelho LM, Povoa PM. Impact of fulminant hepatic failure in C-reactive protein? J Crit Care. 2010; 25:657.

90. Muller B, White JC, Nylen ES, Snider RH, Becker KL, Habener JF. Ubiquitous expression of the calcitonin-i gene in multiple tissues in response to sepsis. J Clin Endocrinol Metab. 2001; 86:396-404.

91. Kopterides P, Siempos II, Tsangaris I, Tsantes A, Armaganidis A. Procalcitonin-guided algorithms of antibiotic therapy in the intensive care unit: a systematic review and meta-analysis of randomized controlled trials. Crit Care Med. 2010; 38:2229-2241

92. Bloos F, Trips E, Nierhaus A, Briegel J, Heyland DK, Jaschinski U, Moerer O, Weyland A, Marx G, Grundling M, Kluge S, Kaufmann I, Ott K, et al. Effect of Sodium Selenite Administration and Procalcitonin-Guided Therapy on Mortality in Patients With Severe Sepsis or Septic Shock: A Randomized Clinical Trial. JAMA Intern Med. 2016; 176:1266-1276.

93. Harbarth S, Holeckova K, Froidevaux C, Pittet D, Ricou B, Grau GE, Vadas L, Pugin J. Diagnostic value of procalcitonin, interleukin-6, and interleukin-8 in critically ill patients admitted with suspected sepsis. Am J Respir Crit Care Med. 2001; 164:396-402.

94. Selberg O, Hecker H, Martin M, Klos A, Bautsch W, Kohl J. Discrimination of sepsis and systemic inflammatory response syndrome by determination of circulating plasma concentrations of procalcitonin, protein complement $3 \mathrm{a}$, and interleukin-6. Crit Care Med. 2000; 28:2793-2798.
95. Jawa RS, Anillo S, Huntoon K, Baumann H, Kulaylat M. Analytic review: Interleukin-6 in surgery, trauma, and critical care: part I: basic science. J Intensive Care Med. 2011; 26:3-12.

96. Jawa RS, Anillo S, Huntoon K, Baumann H, Kulaylat M. Interleukin-6 in surgery, trauma, and critical care part II: clinical implications. J Intensive Care Med. 2011; 26:73-87.

97. Ma S, Ming Z, Gong AY, Wang Y, Chen X, Hu G, Zhou R, Shibata A, Swanson PC, Chen XM. A long noncoding RNA, lincRNA-Tnfaip3, acts as a coregulator of NF-kappaB to modulate inflammatory gene transcription in mouse macrophages. FASEB J. 2017; 31:1215-1225.

98. Wang SY, Fan XL, Yu QN, Deng MX, Sun YQ, Gao WX, Li CL, Shi JB, Fu QL. The lncRNAs involved in mouse airway allergic inflammation following induced pluripotent stem cell-mesenchymal stem cell treatment. Stem Cell Res Ther. 2017; 8:2.

99. Yu XJ, Zou LH, Jin JH, Xiao F, Li L, Liu N, Yang JF, Zou T. Long noncoding RNAs and novel inflammatory genes determined by RNA sequencing in human lymphocytes are up-regulated in permanent atrial fibrillation. Am J Transl Res. 2017; 9:2314-2326.

100. Sun C, Xue L, Zhu Z, Zhang F, Yang R, Yuan X, Jia Z, Liu Q. Insights from lncRNAs Profiling of MIN6 Beta Cells Undergoing Inflammation. Mediators Inflamm. 2016; 2016:9275106.

101. Wang H, Bei Y, Huang P, Zhou Q, Shi J, Sun Q, Zhong J, Li X, Kong X, Xiao J. Inhibition of miR-155 Protects Against LPS-induced Cardiac Dysfunction and Apoptosis in Mice. Mol Ther Nucleic Acids. 2016; 5:e374.

102. Cui YL, Wang B, Gao HM, Xing YH, Li J, Li HJ, Lin Z, Wang YQ. Interleukin-18 and miR-130a in severe sepsis patients with thrombocytopenia. Patient Prefer Adherence. 2016; 10:313-319.

103. Jia Z, Wang J, Shi Q, Liu S, Wang W, Tian Y, Lu Q, Chen P, Ma K, Zhou C. SOX6 and PDCD4 enhance cardiomyocyte apoptosis through LPS-induced miR-499 inhibition. Apoptosis. 2016; 21:174-183.

104. Gao M, Wang X, Zhang X, Ha T, Ma H, Liu L, Kalbfleisch JH, Gao X, Kao RL, Williams DL, Li C. Attenuation of Cardiac Dysfunction in Polymicrobial Sepsis by MicroRNA-146a Is Mediated via Targeting of IRAK1 and TRAF6 Expression. J Immunol. 2015; 195:672-682.

105. Jia P, Teng J, Zou J, Fang Y, Wu X, Liang M, Ding X. Xenon Protects Against Septic Acute Kidney Injury via miR-21 Target Signaling Pathway. Crit Care Med. 2015; 43:e250-e259.

106. Wang X, Wang X, Liu X, Wang X, Xu J, Hou S, Zhang $\mathrm{X}$, Ding Y. miR-15a/16 are upreuglated in the serum of neonatal sepsis patients and inhibit the LPS-induced inflammatory pathway. Int J Clin Exp Med. 2015; 8:5683-5690.

107. Yao L, Liu Z, Zhu J, Li B, Chai C, Tian Y. Clinical evaluation of circulating microRNA-25 level change in 
sepsis and its potential relationship with oxidative stress. Int J Clin Exp Pathol. 2015; 8:7675-7684.

108. Roderburg C, Benz F, Vargas CD, Koch A, Janssen J, Vucur M, Gautheron J, Schneider AT, Koppe C, Kreggenwinkel K, Zimmermann HW, Luedde M, Trautwein C, et al. Elevated miR-122 serum levels are an independent marker of liver injury in inflammatory diseases. Liver Int. 2015; 35:1172-1184.

109. Wang X, Huang W, Yang Y, Wang Y, Peng T, Chang J, Caldwell CC, Zingarelli B, Fan GC. Loss of duplexmiR-223 ( $5 p$ and $3 p$ ) aggravates myocardial depression and mortality in polymicrobial sepsis. Biochim Biophys Acta. 2014; 1842:701-711.

110. Zhao H, Anand AR, Ganju RK. Slit2-Robo4 pathway modulates lipopolysaccharide-induced endothelial inflammation and its expression is dysregulated during endotoxemia. J Immunol. 2014; 192:385-393.

111. Chatterjee V, Beard RJ, Reynolds JJ, Haines R, Guo M, Rubin M, Guido J, Wu MH, Yuan SY. MicroRNA-147b regulates vascular endothelial barrier function by targeting ADAM15 expression. PLoS One. 2014; 9:e110286.

112. Wang H, Yu B, Deng J, Jin Y, Xie L. Serum miR-122 correlates with short-term mortality in sepsis patients. Crit Care. 2014; 18:704.

113. Cheng HS, Sivachandran N, Lau A, Boudreau E, Zhao JL, Baltimore D, Delgado-Olguin P, Cybulsky MI, Fish JE. MicroRNA-146 represses endothelial activation by inhibiting pro-inflammatory pathways. EMBO Mol Med. 2013; 5:1017-1034.

114. Wang L, Wang HC, Chen C, Zeng J, Wang Q, Zheng L, Yu HD. Differential expression of plasma miR-146a in sepsis patients compared with non-sepsis-SIRS patients. Exp Ther Med. 2013; 5:1101-1104.

115. Ma Y, Vilanova D, Atalar K, Delfour O, Edgeworth J, Ostermann M, Hernandez-Fuentes M, Razafimahatratra S, Michot B, Persing DH, Ziegler I, Toros B, Molling P, et al. Genome-wide sequencing of cellular microRNAs identifies a combinatorial expression signature diagnostic of sepsis. PLoS One. 2013; 8:e75918.

116. Sun X, Icli B, Wara AK, Belkin N, He S, Kobzik L, Hunninghake GM, Vera MP, Blackwell TS, Baron RM, Feinberg MW. MicroRNA-181b regulates NF-kappaBmediated vascular inflammation. J Clin Invest. 2012; 122:1973-1990.

117. Wang H, Zhang P, Chen W, Feng D, Jia Y, Xie L. Serum microRNA signatures identified by Solexa sequencing predict sepsis patients' mortality: a prospective observational study. PLoS One. 2012; 7:e38885.

118. Waidmann O, Bihrer V, Pleli T, Farnik H, Berger A, Zeuzem S, Kronenberger B, Piiper A. Serum microRNA-122 levels in different groups of patients with chronic hepatitis $\mathrm{B}$ virus infection. J Viral Hepat. 2012; 19:e58-e65.

119. Wang JF, Yu ML, Yu G, Bian JJ, Deng XM, Wan XJ, Zhu KM. Serum miR-146a and miR-223 as potential new biomarkers for sepsis. Biochem Biophys Res Commun. 2010; 394:184-188.

120. Vasilescu C, Rossi S, Shimizu M, Tudor S, Veronese A, Ferracin M, Nicoloso MS, Barbarotto E, Popa M, Stanciulea O, Fernandez MH, Tulbure D, Bueso-Ramos CE, et al. MicroRNA fingerprints identify miR-150 as a plasma prognostic marker in patients with sepsis. PLoS One. 2009; 4:e7405.

121. Wang HJ, Deng J, Wang JY, Zhang PJ, Xin Z, Xiao K, Feng D, Jia YH, Liu YN, Xie LX. Serum miR-122 levels are related to coagulation disorders in sepsis patients. Clin Chem Lab Med. 2014; 52:927-933.

122. Xiao C, Calado DP, Galler G, Thai TH, Patterson HC, Wang J, Rajewsky N, Bender TP, Rajewsky K. MiR-150 controls $\mathrm{B}$ cell differentiation by targeting the transcription factor c-Myb. Cell. 2007; 131:146-159.

123. Wang H, Meng K, Chen W, Feng D, Jia Y, Xie L. Serum miR-574-5p: a prognostic predictor of sepsis patients. Shock. 2012; 37:263-267.

124. Flierl MA, Rittirsch D, Huber-Lang MS, Sarma JV, Ward PA. Molecular events in the cardiomyopathy of sepsis. Mol Med. 2008; 14:327-336.

125. Sluijter JP, Doevendans PA. Sepsis-associated cardiac dysfunction is controlled by small RNA molecules. J Mol Cell Cardiol. 2016; 97:67-69.

126. Kim WY, Hong SB. Sepsis and Acute Respiratory Distress Syndrome: Recent Update. Tuberc Respir Dis (Seoul). 2016; 79:53-57.

127. Sakr Y. Heparin-induced thrombocytopenia in the ICU: an overview. Crit Care. 2011; 15:211.

128. Vincent JL, Yagushi A, Pradier O. Platelet function in sepsis. Crit Care Med. 2002; 30.

129. Riedemann NC, Guo RF, Ward PA. Novel strategies for the treatment of sepsis. Nat Med. 2003; 9:517-524.

130. Risoe PK, Ryg U, Wang YY, Rutkovskiy A, Smedsrod B, Valen G, Dahle MK. Cecal ligation and puncture sepsis is associated with attenuated expression of adenylyl cyclase 9 and increased miR142-3p. Shock. 2011; 36:390-395.

131. Zhang AQ, Gu W, Zeng L, Zhang LY, Du DY, Zhang M, Hao J, Yue CL, Jiang J. Genetic variants of microRNA sequences and susceptibility to sepsis in patients with major blunt trauma. Ann Surg. 2015; 261:189-196.

132. Goodwin AJ, Guo C, Cook JA, Wolf B, Halushka PV, Fan H. Plasma levels of microRNA are altered with the development of shock in human sepsis: an observational study. Crit Care. 2015; 19:440.

133. Wang HJ, Zhang PJ, Chen WJ, Feng D, Jia YH, Xie LX. Four serum microRNAs identified as diagnostic biomarkers of sepsis. J Trauma Acute Care Surg. 2012; 73:850-854.

134. Matouk IJ, Halle D, Gilon M, Hochberg A. The noncoding RNAs of the H19-IGF2 imprinted loci: a focus on biological roles and therapeutic potential in Lung Cancer. J Transl Med. 2015; 13:113. 
135. Hinkel R, Penzkofer D, Zuhlke S, Fischer A, Husada W, Xu QF, Baloch E, van Rooij E, Zeiher AM, Kupatt C, Dimmeler $\mathrm{S}$. Inhibition of microRNA-92a protects against ischemia/ reperfusion injury in a large-animal model. Circulation. 2013; 128:1066-1075.
136. Janssen HL, Reesink HW, Lawitz EJ, Zeuzem S, RodriguezTorres M, Patel K, van der Meer AJ, Patick AK, Chen A, Zhou Y, Persson R, King BD, Kauppinen S, et al. Treatment of HCV infection by targeting microRNA. N Engl J Med. 2013; 368:1685-1694. 